\title{
The Level of Community of Inquiry (CoI) Presences in Online Classes among MSU BTESL Students
}

\section{Mohammad Ali Al-Saggaf', Amierah Syazwaniey Rosli ${ }^{1}$}

${ }^{1}$ Management and Science University, Malaysia

Corresponding author: Mohammad Ali Al-Saggaf [mohammad_ali@msu.edu.my]

\begin{tabular}{llll}
\hline Received: 13.03 .20201 & • & Accepted: 24.03.2021 & Published: 31.03 .2021 \\
\hline
\end{tabular}

\begin{abstract}
Community of Inquiry (CoI) is a framework that acknowledges the importance of the environment in shaping the educational experience. According to this framework, teaching, social, and cognitive presences are essential for an optimal online learning experience. The purpose of this study is to identify the level of each of these presences in online classes among Management and Science University (MSU) Bachelor in Education - TESL (Hons). The instrument used for the research tool was adapted from the original CoI framework survey, (Arbaugh et al., 2010). The questionnaire consists of 20 items; six items for teaching presence, another six items for social presence, and eight items for cognitive presence. 263 students who are currently doing the programme participated in the study. The findings concluded that all three presences are present in high or strong level in online classes among MSU BTESL students with the most substantial presence in online classes among MSU BTESL students being the cognitive presence, followed by the teaching presence and lastly the social presence.
\end{abstract}

Keywords: Community of Inquiry; teaching presence; social presence; cognitive presence

\section{Introduction}

According to Nguyen (2015), "the physical "brick and mortar" classroom is starting to lose its monopoly as the place of learning." (p.1) This is true, especially in today's world, with the current pandemic of Covid-19. This lethal and contagious Corona Virus outbreak has been profoundly affecting not only the global economy but also other sectors, including the educational sector. This pandemic has forced many educational institutions to shut down temporarily. For this reason, online classes are now becoming the cornerstone of the educational sector. For this reason, it is essential to address the essence of an effective online learning environment. This essence can be understood through the Community of Inquiry (CoI) model.

$\mathrm{CoI}$ is a framework that highlights the roles of the environment in shaping the educational experience. According to the framework, because physical presence is already lacking in an online learning environment, three elements are essential to create a meaningful and deep online learning educational experience. The elements are social, cognitive, and teaching presence. This framework suggests that the intersection of these three presences is where the essence of the community of inquiry occurs for a purposeful collaboration and learning to take place.

The lack of physical presence in online classrooms calls for the Community of Inquiry framework, suggesting that three types of presences are essential for an effective online learning 
environment. Teaching presence is vital because, according to Persico et al. (2010), it is "the binding element in cultivating a learning community". Social presence, on the other hand, is important to help learners express themselves as real people. Finally, cognitive presence is important because it represents the three most important processes in learning which are critical thinking, collaborative problem-solving, and meaning establishment. The lacking of one of the three presences may result in simply, an ineffective online learning environment. Thus, it is important to measure the level of each of the presences as the foundation of effective online learning is said to be generally comparable to the basis of efficacious learning.

A need for this study is grounded on a few existing studies. According to Allen and Seaman (2013), there are higher rates of online courses and enrolment in public education over the years but a low rate of faculty confidence and institutional strategies for online growth. This study is significant because it will look into the level of presence based on the Community of Inquiry (CoI) model. By identifying these presences levels, online instructors can make necessary amendments to improve students' learning experience. Corresponding to that objectives, the following research questions are proposed:

a. What is the level of teaching presence in online classes among MSU BTESL students?

b. What is the level of social presence in online classes among MSU BTESL students?

c. What is the level of cognitive presence in online classes among MSU BTESL students?

\section{Literature Review}

Learning is understood through four broad theoretical approaches, which are behaviourism, cognitive, constructivism, and social constructivism. The Community of Inquiry (CoI) is developed based on the social constructivism theoretical approach which suggests that knowledge is coconstructed.

\subsection{Theoretical Framework}

The Community of Inquiry framework, or better known as CoI, is a framework suggested by Rourke et al. (2000). It was first developed for their study to understand the factors or conditions needed to take deep and meaningful learning in an online learning environment. According to Garrison (2011), as cited in Garrison and Akyol (2013), an educational community of inquiry refers to " a group of individuals who collaboratively engage in purposeful critical discourse and reflection to construct personal meaning and confirm mutual understanding" (p. 2). This framework highlights three different presences as essential elements for that, which are: i) social presence, ii) teaching presence, and iii) cognitive presence.

\section{i. Teaching Presence}

According to Alman et al. (2012), teaching presence is defined simply as the relationship that serves professional and instructional roles between instructors and learners. The most major role for an instructor is to facilitate and manage the course. This definition is supported by Anderson et al. (2001) as they elucidate teaching presence as the "design, facilitation and direction of cognitive and social processes to realize personally meaningful and educationally worthwhile learning outcomes" (p. 5). Alman et al. (2012) further cited Lowenthal and Parscal (2008), which states that while teachers' guide in an online learning environment is often considered as only a side guide, it does not necessarily mean that the instructor is completely absent or uninvolved in the course. This supports that teaching presence does exist in an online learning environment. However, unlike in physical classes, keeping 
learners engaged in an online learning environment is much more complex and requires a more sustained teaching presence.

This instructor presence or known as teaching presence can be analysed using the three categories Anderson et al. (2000) suggested; direct instruction (DI), instructional design (ID), and facilitation of discourse (FD). In short, DI refers to the pedagogical and intellectual roles of an instructor. ID, on the other hand, includes the managerial and organizational roles, and FD governs itself on the instructor's social roles.

\section{ii. Social Presence}

Social presence theory was first developed by social psychologist Short, Williams, and Christie (1976). They define it as the ability of communication media to transmit social cues.

It refers to learners' ability to themselves into the community of inquiry. By doing so, they can present themselves as 'real people' even though they are behind the screens. Social presence involves a level of interaction among not only instructors and learners but also learners among themselves. This interaction is what is said to determine the learners' motivation and willingness to participate in their own and peers' meaning-making process. Thus, it can be said that social presence carries a significant influence on an online learning course's effectiveness. Johnson, Hornick, and Salas (2008), as cited in Izmirli (2017), agree on the significant role social presence has in online learning. Izmirli (2017) also cited Swan et al. (2009), which claims that social presence directly affects collaboration and community development in an online course. According to Akcaoglu and Lee (2016), social presence is not easy to achieve but it is an essential element in online learning. This is because establishing a social connection is one of the basic needs for humans and this need extends even in an online environment.

According to Rourke et al. (2000), three behavioral categories are associated with social presence; emotional expression, open communication, and group cohesion. Garrison (2009) provides a more recent definition of the presence, as cited in Kreijns et al. (2014), these three categories can be regarded as "phases of a process in which first a shared social identity - derived from the purpose of the course - is the primary concern, and then later, is the basis for the formation of interpersonal relationships." (p9).

Emotional expression, or also known as effective expression, refers to the socioemotional components of communication to form interpersonal relationships. On the other hand, open communication refers to the interactive and purposive nature of communication, while group cohesion refers to the community's shared identity and its' collaborative behavioural intention. Each of these categories can be identified using different indicators. For instance, the indicators of emotional or affective expression may be in the form of expressions of emotions (i.e., including emojis or emoticons), humour integration (i.e., using sarcasm), and self-disclosure (i.e., disclosing a secret or other personal detail of oneself). The indicators of open communication can be in the form of engaging in a conversation by continuing a thread of messages, quoting others, referring to previously said messages explicitly, posing questions, receiving/providing feedback, giving comment or compliment, or simply expressing one's appreciation and agreement/disagreement. Lastly the use of vocatives such as addressing someone using their name, using inclusive pronouns like regarding themselves as a 'we/us' is an easy indicator of group cohesion. 


\subsection{Community of Inquiry Presences in Online Classrooms}

Adopting the Community of Inquiry (CoI) framework like the present study, Shea and Bidjerano (2012) conducted a research study to explore how students' perceptions of presence and self-regulated learning differs in hybrid and fully online learning environments. The study participants consisted of 2010 college students from 38 different higher education institutions who share a shared online learning network. The study's findings highlight the importance of teaching presence and social presence quality in the online learning environment as the findings indicate that the characteristics of which learner brings in the learning environment when the other social and teaching presence are inadequate are what makes a cognitive presence. The findings also indicate that students in fully online courses blended experience lower levels of the three presences in comparison to in blended courses.

Blaine (2019) undertook a qualitative study in the north-eastern United States using focus group transcripts to identify the distinct ways instructors and learners perceive interaction. Similar to the present study, this study also aims to identify the quality of social and teaching presence not only in fully-online courses but also blended ones. The research findings suggest that teachers and students indeed have different views on interaction and course development. It reveals that teachers generally were positive in their view of interaction in the course, which is not the case with students. These findings also concluded that there is an additional valid presence to the community of inquiry, learning presence.

Choo et al. (2019) examined a study exploring the perceptions of undergraduate students of the three CoI presences and their correlations to students' course satisfaction. Similar to the present study, their study also adapted the original CoI survey (Rourke et al., 2000). It was carried out over three semesters in 10 online graduate courses at a public university in the Midwestern United States. The findings indicate that the teaching presence and cognitive presence positively influence online course satisfaction. In addition to that, they also justified the possible reason that social presence does not come as a significant predictor like some other previous researches are that the population is not fully online students, which makes them able to have interaction face to face instead of online.

In Malaysia, Khodabandelou et al. (2014) conducted a research study to determine the relationship between Community of Inquiry and perceived learning in blended learning environments. This study also looks at the effect of gender on this relationship. In this study, the CoI questionnaire and perceived learning scale were distributed to 348 undergraduate students in a blended program from three public universities. The findings indicated that there are substantial differences between the CoI components and the perceived learning of both genders. However, it is said that to moderate gender in the relationship between $\mathrm{CoI}$ and perceived learning, the differences they found are inadequate.

Traver et al. (2014) conducted a study that examined the correlation between the perceptions of community college students towards CoI presences and their completion of blended courses. The study took place at a community college in the United involving 444 students from a total of seventeen different classes as participants. Two online surveys; a pre-test and also a post-test is used for this study. The questionnaire for the survey was adopted from Shea and Bidjerano's (2010) CoI survey instrument which is the original CoI survey with an added measure of learning presence. The results turn to be corresponding to that of previous research (Shea \& Bidjerano, 2010) whereby it finds that students' perception in teaching, social and cognitive presences are moderated by the demographic and status variables. This means that students perceive these presences as subject to change depending on their prior online learner experiences. It is reported that students who have taken more than two or more fully-online or blended courses in the past tended to perceive higher CoI presences in comparison to students who are taking it for the first time. 
Harrel and Wendt (2019) undertook a study which examined the way blended learning affects high school leaner's community of inquiry (CoI) and their perceived learning in comparison to online instructions. This study followed a causal-comparative design to identify the possible causal relationships between the type of learning environments and the three presences. The study took place at an online-based public charter school located in the United States. The data used for the analysis was collected from the school's archival to identify the programme effectiveness in the year 20152016. It involved 172 participants of various grades and English levels, 46 of which were participated in only blended learning English courses. The remaining participants were enrolled in only online programs of study. The results show that the blended learning students and online learning students have a statically significant difference in their composite of CoI scores. For this reason, the study did a separate dependent variable on the individual presences and found that the only significant difference between the two groups was their social presence.

Pillai and Sivathanu (2019) carried out an empirical study that aimed to determine the online learning experience of massive open online courses (MOOCs) among the students in India. This unique research also looks at the research questions using two other contextual factors which are technical barrier and hedonic motivation. The objectives of the research are to provide a theoretical model using the CoI framework to identify students' online learning experience and to provide empirical validation of the proposed framework. The primary data was collected using a survey method of a structured questionnaire which was distributed to 1, 390 undergraduate and postgraduate students who were taking MOOCs from colleges, universities, and the government higher education institutions in Pune and Mumbai cities in India. The results reveal that both cognitive presence and social presence are influenced by teaching presence. It also finds that social presence impacts cognitive presence. In addition to that, the findings also reveal that the three presences highly influence the learning experience in the MOOCs which validates the model. This study also found that technical barrier influence does influence learning experience but it is not significant and hedonic motivation positively influences the MOOCs learning experience.

Another group of researchers, Rockinson-Szapkiw, Wendt, Wighting, and Nisbet (2016) also conducted research associated with CoI. The study uses a predictive correlational and hierarchical multiple regression to examine whether students' sense of $\mathrm{CoI}$ and perceived learning predicted their course points. It involved a convenience sample with a total of 131 students who enrolled in graduatelevel online education technology courses in a private institution in Virginia. It uses the CoI framework survey (Arbaugh et al., 2010) as a predictor variable that assesses participants' perceived sense of the three presences. The findings show that students who used both asynchronous and synchronous technologies in their course scored relatively higher points in their course in comparison to those who used only asynchronous technologies. It indicates that the fundamental constructs of the CoI theory and perceived learning roles are an effective predictor of final course points.

Shea and Bidjerano (2008) conducted research to identify whether the CoI instrument and model can explain the difference in levels of students' online courses learning and satisfaction in the higher education context. and model of Community of Inquiry (CoI) also discovered that social presence does not predict learner satisfaction. Like the present study, this research also used the original and validated CoI framework survey as the research tool. This research includes a number of 1366 samples and the results indicated that the items in the instrument are indeed cohesive to provide factors that can be interpreted and comprehended to reflect not only the framework scale as a whole but also the subscales. Using multiple regression analysis, the results indicated that social presence does not predict learner satisfaction. 
Cho and Tobias (2016) carried out a study to analyse the role of online discussion in students' learning experience. It is measured using the CoI framework, learner time on the online platform, satisfaction, and achievement. This research follows an experimental design whereby it involved students who participated in three different sections of a sophomore-level online course in the Midwestern United States. This online course is taught using different conditions within three consecutive semesters by the same instructor. The conditions are: completely zero discussion for the first semester, with discussion but without instructor participation in the second semester, and discussion with active instructor participation in the third semester. The results reveal that there is no major difference among the conditions in the cognitive presence and instructors' teaching presence. However, a major difference is identified in social presence among the conditions. There is also no significant difference found in time spent, course satisfaction, and student achievement.

Another research done in the past related to the current study was also conducted by a group of researchers namely Arbaugh, Bangert, and Innes (2010). This group of researchers sought to examine the disciplinary differences in perceptions of the three CoI presence. This study took place in two institutions in the United States with more than 1500 students across seven as the participants. The collection of data was done using a web-based survey which is done on the last week of the course. The web-based survey consisted of items relating to the perceptions of students towards the learning environment, the course's system of management, the efficiency of instructors, the information they managed to acquire as well as their overall satisfaction with the Internet being the course delivery medium. The findings show significant disciplinary differences especially when cognitive presence being in soft, applied disciplines in comparison to other disciplines.

\section{Materials and Methods}

\subsection{Research Design}

After taking the research objectives and questions as well as the designed framework into account, the design employed for this research is quantitative. A quantitative study refers to a formal and systematic process that uses numerical data to obtain any information related to the research. This particular type of research allows researchers to compile data onto the graphical representation of data such as using a graph or chart. Most of the information in quantitative research is valued and presented statistically.

\subsection{Sample}

This research used a convenience sampling method. The population of this research is Management \& Science University (MSU) Bachelor in Education - TESL (Hons) students. There were a total of 830 students in BTESL altogether which makes up the population. The sample size of this research was employed using Slovin's formula; with a confidence level of 95\% and 5\% of margin of error. Based on this calculation, the approximate sample size for the selected population was 263 . However, it is said that to be able to generalise the findings from the sample to the population as a whole, the sample must be representative of the population. Thus in order to ensure good representativeness of the population, the sample was also stratified according to gender as well as educational year.

\subsection{Instrument}

The research tool for this research paper is a questionnaire adapted from the original, reliable, and validated Community of Inquiry (CoI) framework survey (Arbaugh et al., 2008). Because there were 
too many items in the original instrument, a slight modification was made by omitting a few of the items which were not significant to the research questions. The items were reduced from 34 -items to only 20 -items. For this reason, a pilot test was conducted to determine the validity and reliability of the instrument. The online questionnaire comprises two sections. The first section consisted of the demographics details which bring in a total of 4 items. Following that, the second section consisted of 20 items which correspond to the three essential presences using a 5-point Likert scale ( $1=$ Strongly disagree, 2= Disagree, $3=$ Natural, 4= Agree, 5= Strongly Agree) .

\subsection{Pilot Study}

A pilot study refers to a small-scale study that is usually carried out before the implementation of the actual research, especially if it involves a newly developed instrument as it can determine the reliability and validity of an instrument. It is regarded as one of the most essential stages in a research project. This is mainly because it can help identify any unforeseen potential problem areas and deficiencies in the research instruments and protocol. Foreseeing these problems allows researchers to take the necessary steps to adjust their research design or overcome the problems in general. As a result, they will not only be able to save their energy and money but most importantly, time which is often an enemy in a research project.

For these reasons, a pilot study was also conducted for this study. It was conducted on 9th November 2020. The online survey questionnaire was generated in Testmoz and the link to it was distributed through WhatsApp. Each of the respondents was approached personally. It took approximately 24 hours to collect the targeted minimum number of responses which was 20. However, this study managed to collect 30 responses. The participants for this pilot study were Bachelor in Education TESL (Hons) (BTESL) students. These students were those who are also taking the subject Research Project in the current semester. The responses were transferred into Statistical Package of Social Sciences (SPSS) software to analyse its Cronbach Alpha. The reliability Cronbach alpha for all 20 items, excluding the demographic background, is 0.782 .

\subsection{Procedures and Data Analysis}

After confirming the reliability and validity of the instrument, the researcher began distributing the online survey to collect data. The distribution of the link only begun once the approval is conceded by the supervisor. This distribution was done through the messaging app, WhatsApp. After gathering enough responses, the data was transferred into Microsoft Excel before tabulating it using the Statistical Package for the Social Sciences (SPSS). All analysis in this study was done using this software. The analysis uses percentages and frequencies as well as calculation of average mean scores and standard deviations. Charts, graphs, and tables were also provided to represent the data for it be to seen, interpreted, and understood better.

\section{Results and Discussion}

\subsection{Demographic Information}

Based on the data shown in Figure 1, it can be seen that $60 \%$ of the respondents were females, and $40 \%$ of them were males. This shows that the standard of this research project which suggests that the 4:6 male and female ratio is needed for good representativeness is followed. This research managed to gather a total of 355 responses. However, 92 responses have been discarded to adhere to this standard of good representativeness, leaving only the exact calculated sample size, which is 263 . The responses are garnered from one hundred and fifty-eight (158) females and one hundred and five (105) males. 


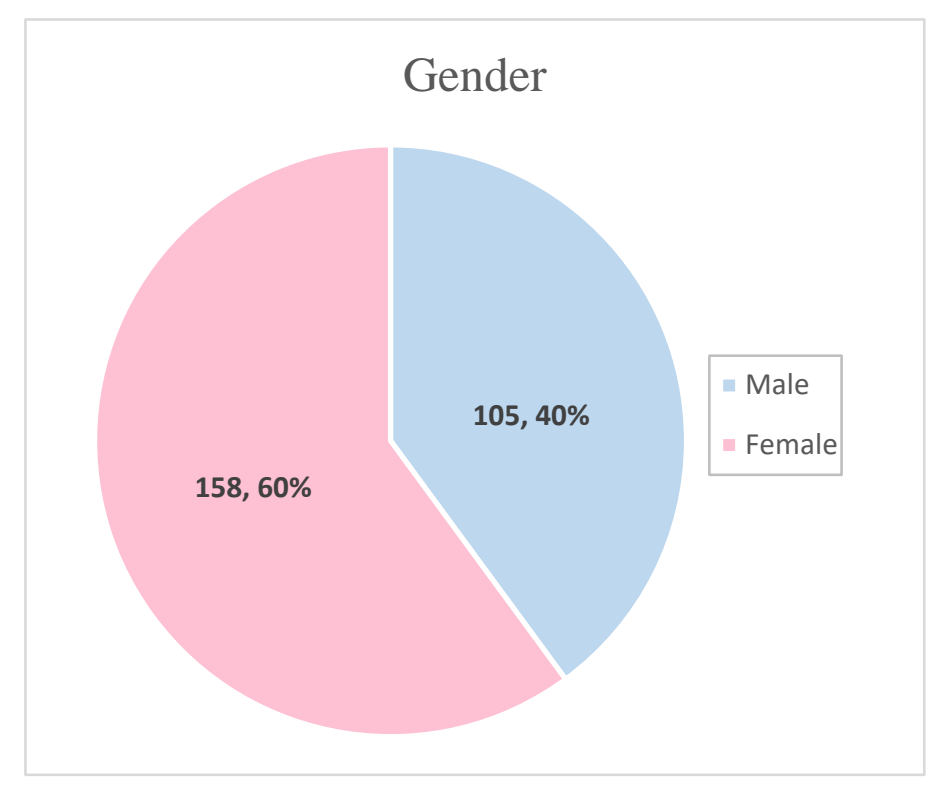

Figure 1. Gender Frequency and Percentage

Based on the data shown in Figure 2 below, most of the respondents were between $21-23$ years old, which includes one hundred and sixty-eight (168) respondents. The second-highest age range was 24 - 26, with fifty-seven (57) respondents. The remaining thirty-eight (38) respondents were students between the age of 18 to 20 .

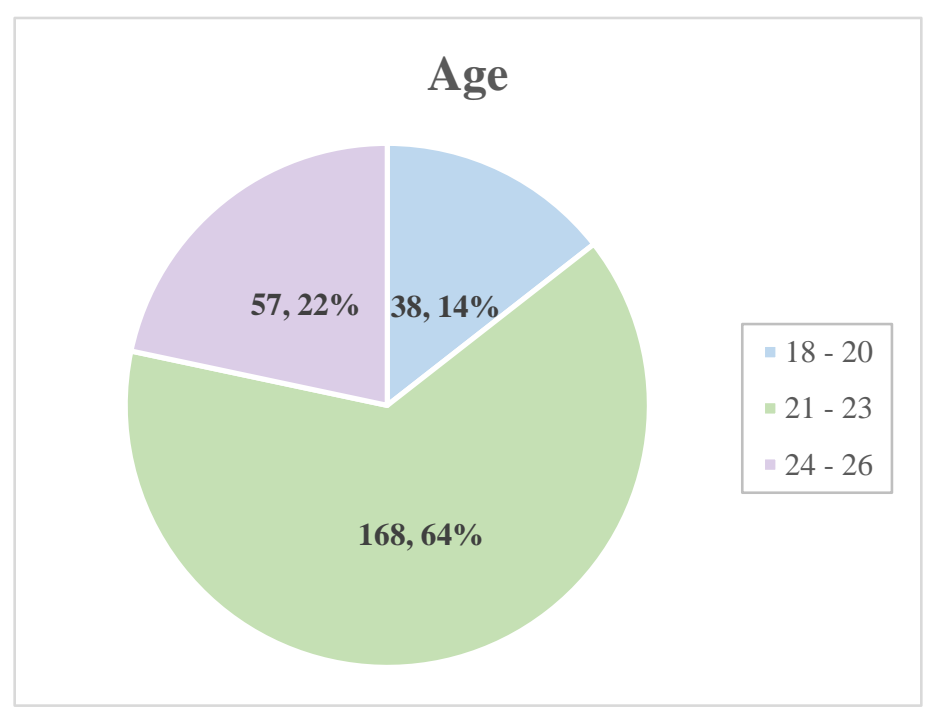

Figure 1. Age Frequency and Percentage

Figure 3 demonstrates the last of the demographic background question that has asked for the year of study of each respondent who partook in the research study. Like gender, this demographic information also requires a specific target to be met for the sample's good representativeness. The highest number of respondents comes from Year 3 which involves one hundred and fifty (150) students. The second highest is Year 1 with fifty-eight (58) students. Last but not least, the remaining fifty-five (55) students are from Year 2. 


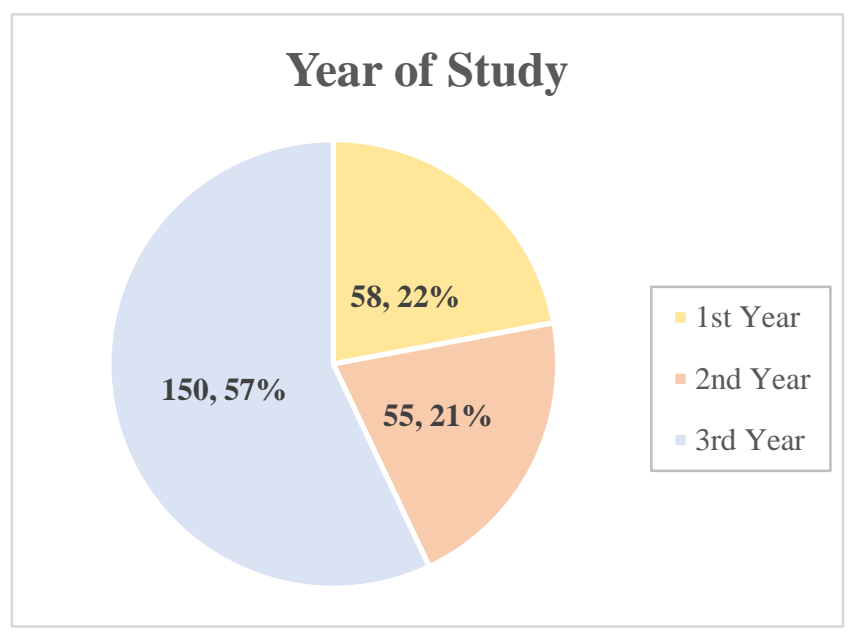

Figure 2. Year of Study Frequency and Percentage

\subsection{Teaching Presence}

Table 1. Teaching Presence

\begin{tabular}{|c|c|c|}
\hline Items & Mean & Std. Deviation \\
\hline $\begin{array}{l}\text { 1. The instructors clearly communicated course topics and goals in the } \\
\text { online classes. }\end{array}$ & 3.5932 & .85486 \\
\hline $\begin{array}{l}\text { 2. The instructors clearly communicated due dates/time frames for online } \\
\text { learning activities }\end{array}$ & 3.8327 & .87510 \\
\hline $\begin{array}{l}\text { 3. The instructors were helpful in identifying areas of agreement and } \\
\text { disagreement on course topics that helped me to learn online. }\end{array}$ & 3.6198 & .87083 \\
\hline $\begin{array}{l}\text { 4. The instructor helped to keep course participants engaged and } \\
\text { participating in productive dialogue. }\end{array}$ & 3.6388 & .87083 \\
\hline $\begin{array}{l}\text { 5. The instructors helped to focus online discussion on relevant issues in a } \\
\text { way that helped me to learn. }\end{array}$ & 3.7414 & .88330 \\
\hline $\begin{array}{l}\text { 6. The instructors provided feedback that helped me understand my } \\
\text { strengths and weaknesses relative to the course's goals and objectives. }\end{array}$ & 3.6122 & .93784 \\
\hline
\end{tabular}

Based on Table 1, it can be seen that most respondents had chosen 'Agree' and 'Neutral' for all of the items. The highest mean score for teaching presence is obtained by Item 2, "The instructors clearly communicated due dates/time frames for online learning activities," with a mean score of 3.83. This proves that learners are well-informed of the due dates, such as assignment or task submissions and et cetera. Item 5, "The instructors helped to focus online discussion on relevant issues in a way that helped me to learn," obtained the second highest mean score, which is 3.74. The third highest mean score is obtained by Item 4, "The instructors helped to keep course participants engaged and participating in productive dialogue." This proves that instructors in the online course conduct activities that allow discussions among learners. Contrarily, Item 1, "The instructors clearly communicated course topics and goals in the online classes," garnered the lowest mean score of 3.59. Even though the mean score indicates that most students agree with the statement, the instructors can further enhance the online learning experience by improving their communication course topics and goals.

Based on the descriptive statistic mean score, the average mean obtained for all six items representing teaching presence is 3.67, indicating a high level of teaching presence in online classes among MSU BTESL students. 


\subsection{Social Presence}

Table 2. Social Presence

\begin{tabular}{lcc}
\hline \multicolumn{1}{c}{ Items } & Mean & Std. Deviation \\
\hline & & \\
7. Getting to know other course participants during online class sessions & 3.5361 & 1.00648 \\
gave me a sense of belonging in the course. & & \\
8. I was able to get to know some of the course participants. & 3.6084 & .96635 \\
9. I felt comfortable conversing through the online medium. & 3.4753 & 1.06217 \\
10. I felt comfortable participating in the online course discussions. & 3.4753 & 1.06217 \\
11. I felt comfortable disagreeing with other course participants while still & 3.4905 & .98795 \\
maintaining a sense of trust. & & 1.03281 \\
12. Online discussions helped me to develop a sense of collaboration. & 3.5323 & \\
\hline
\end{tabular}

Based on Table 2 most of the respondents chose "Strongly Agree," "Agree," and "Neutral." The highest mean score for social presence is Item 8, "I was able to get to know some of the course participants," with a 3.61 mean score. Almost half of the respondents, 122 out of 263 respondents (46.4\%), strongly agreed with the statement. The second highest mean score is obtained by Item 12 with the statement "Online discussions helped me to develop a sense of collaboration". This item garnered a mean score of 3.53 , whereby $43 \%$ or 113 of the respondents agreed with it. This shows that discussions conducted in online classes among MSU BTESL students have helped them work together in creating something new under a shared goal. This is most likely to be for working on group projects together as they exchange ideas and information. The third highest mean for the social presence is garnered by Item 7, "Getting to know other course participants during online classes sessions gave me a sense of belonging in the course." This indicates that most of the students do feel a sense of belonging in the course as they have answered in the previous item with the top highest mean score that they were able to know some of the course participants.

The lowest mean score for this set of items is obtained by Item 9 and Item 10: both with the mean score of 3.48. The statement for Item 9 is "I felt comfortable conversing through the online medium," and the statement for Item 10 is "I felt comfortable participating in online course discussions." As can be seen, these two items are very closely related as they are representing open communication in the classes. Therefore, these two items' findings indicate that students feel uncomfortable taking an active part in open communication in online classes.

Based on the descriptive statistic mean, the average mean obtained for all six items representing social presence is 3.52 , indicating a high social presence in online classes among MSU BTESL students. This proves that instructors in online classes among MSU BTESL students can still further improve students' online learning experience by enhancing this social presence level. This is important as the findings of Richardson et al. (2017) suggest that social presence can positively influence satisfaction and perceived learning.

\subsection{Cognitive Presence}

Table 3. Cognitive Presence

\begin{tabular}{lcc}
\hline Items & Mean & Std. Deviation \\
\hline $\begin{array}{l}\text { 13. Problems posed in online classes increased my interest in course } \\
\text { issues. }\end{array}$ & 3.3498 & 1.05175 \\
14. Online course activities piqued my curiosity. & 3.3992 & 1.04312
\end{tabular}




\begin{tabular}{|c|c|c|}
\hline $\begin{array}{l}\text { 15. I utilised a variety of information sources to explore problems posed } \\
\text { in online classes. }\end{array}$ & 3.8251 & .89944 \\
\hline $\begin{array}{l}\text { 16. Brainstorming and finding relevant information helped me resolve } \\
\text { content-related questions. }\end{array}$ & 3.9658 & .86203 \\
\hline $\begin{array}{l}\text { 17. Combining new information helped me answer questions raised in } \\
\text { online course activities. }\end{array}$ & 3.9125 & .81725 \\
\hline $\begin{array}{l}\text { 18. Online learning activities helped me construct solutions to content- } \\
\text { related problems. }\end{array}$ & 3.7947 & .89296 \\
\hline $\begin{array}{l}\text { 19. I can describe how I am going to apply the knowledge learned in online } \\
\text { classes into practice. }\end{array}$ & 3.7757 & .85553 \\
\hline $\begin{array}{l}\text { 20. I can apply the knowledge created in my online classes to my work or } \\
\text { other non-class-related activities. }\end{array}$ & 3.8631 & .81276 \\
\hline
\end{tabular}

Based on Table 3, most of the respondents chose "Strongly Agree," "Agree," and "Neutral." The highest mean score for cognitive presence is garnered by Item 16, "Brainstorming and finding relevant information helped me resolve content-related questions," with a mean score of a whopping 3.97. Item 17, "Combining new information helped me answer questions raised in online course activities", garnered the second highest mean score of 3.91. This item obtained 134 agrees out of 263 responses. Conclusively, this indicates that the BTESL students in online classes in MSU use information or knowledge to solve the problems posed in the online course activities. The third highest mean is obtained by the last item of the questionnaire, Item 20, "I can apply the knowledge created in my online classes to work or other non-class related activities". The findings show that more than half of the respondents $(51 \%)$ agree with this statement. This means that the students know how to apply their knowledge in online classes in real-life situations. This is a good thing because students should be able to use knowledge and skills in exams and other challenges inside and outside of the classrooms.

Based on the descriptive statistic mean score, the average mean obtained for all eight items representing cognitive presence is 3.74 , indicating that this presence is also present at a high level in online classes among MSU BTESL students. The previous research question reveals that the social presence is present at the lowest level, which means these findings are relevant to Shea and Bidjerano (2009) findings, which found if the teaching presence students who experience low social presence would still experience high cognitive presence.

\subsection{Overall Findings}

The overall findings show that the level of all three presences in online classes among Management and Science University (MSU) Bachelor in Education - TESL (Hons) (BTESL) students is high. This means that the assumption that has been drawn by this researcher is debunked as the researcher assumed that the social presence level in online classes among MSU BTESL students would be low. However, based on Figure 4, the researcher would also like to pinpoint that if these presences were to be ranked according to the levels based on the average mean scores, the social presence would still be the lowest in level with an average mean of 3.52. With an average mean of 3.74, cognitive presence is the most substantial presence in online classes among MSU BTESL students, and the second most substantial is the teaching presence, with an average mean of 3.67 (see Figure 4). 


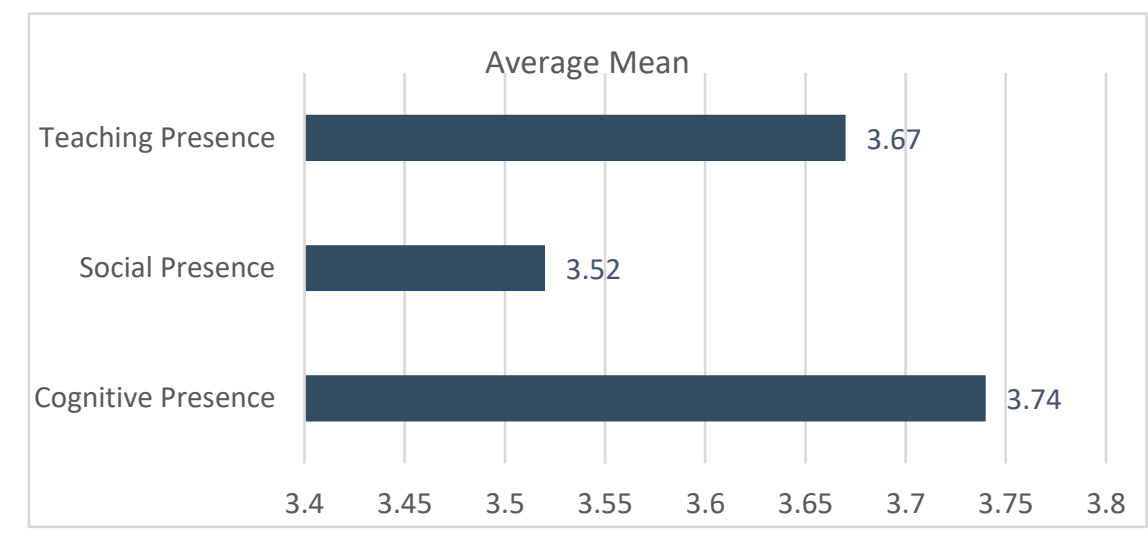

Figure 3. Overall findings

\section{Conclusion and Implications}

Conclusively, all 20 items were able to provide answers to the three research questions. It shows that all three presences are present at a strong level in online classes among MSU BTESL. These findings indicate the efficacy of the online classes. However, these findings cannot be generalised to all courses in MSU. Thus, the same study is recommended to be conducted in other courses, or even subjects as the first step to improve students' learning experience as the foundation of effective online learning are said to be generally comparable to the basis of efficacious learning.

Considering how online learning implementation is taking its course in the current situation, it is expected that this research topic could contribute significant information towards the field of education. Researchers with similar topic interests can use this research paper as a reference for them to understand the level of Community of Inquiry (CoI) presence in online classes, particularly among university students in Malaysia. In fact, they can use this paper as a foundation to conduct a much more in-depth study of their own. However, this researcher recommends that they also look into the correlation of the presences for more significant findings, which the researcher has not been able to do due to time constraints. In addition to that, to make the findings more focused; future researchers are recommended to look at these levels in case of studies by identifying them in individual subjects rather than a programme as a whole.

\section{References}

Akcaoglu, M., \& Lee, E. (2016). Increasing social presence in online learning through small group discussions. The international review of research in open and distributed learning, 17(3).

Alman, S. W., Frey, B. A., \& Tomer, C. (2012). Social and cognitive presence as factors in learning and student retention: An investigation of the cohort model in an iSchool setting. Journal of Education for library and Information Science, 290-302.

Allen, I. E., \& Seaman, J. (2013). Changing course: Ten years of tracking online education in the United States. Sloan Consortium.

Anderson, T., Liam, R., Garrison, D. R., \& Archer, W. (2001). Assessing teaching presence in a computer conferencing context. 
Arbaugh, J. B., Bangert, A., \& Cleveland-Innes, M. (2010). Subject matter effects and the community of inquiry (CoI) framework: An exploratory study. The internet and higher education, 13(1-2), $37-44$.

Blaine, A. M. (2019). Interaction and presence in the virtual classroom: An analysis of the perceptions of students and teachers in online and blended Advanced Placement courses. Computers \& Education, 132, 31-43.

Cho, M. H., \& Tobias, S. (2016). Should instructors require discussion in online courses? Effects of online discussion on community of inquiry, learner time, satisfaction, and achievement. International Review of Research in Open and Distributed Learning, 17(2), 123140.

Choo, J., Bakir, N., Scagnoli, N. I., Ju, B., \& Tong, X. (2020). Using the Community of Inquiry framework to understand students' learning experience in online undergraduate business courses. TechTrends, 64(1), 172-181.

Doring, A. (2015). Online knowledge sharing: investigating the community of inquiry framework and its effect on knowledge sharing behavior in online learning environments.

Garrison, R. (2011). e-learning in the 21st Century: a framework for research and practice. Second edition. Routledge: New York.

Garrison, D. R., \& Akyol, Z. (2013). The community of inquiry theoretical framework. Handbook of distance education, 3, 104-120.

Harrell, K. B., \& Wendt, J. L. (2019). The impact of blended learning on community of inquiry and perceived learning among high school learners enrolled in a public charter school. Journal of Research on Technology in Education, 51(3), 259-272.

Hosler, K. A. (2009). Examining the effects of teaching presence on student satisfaction in fully online learning environments. 2009 Annual Proceedings-Louisville, 2, 78.

Izmirli, S. (2017). Can we use Facebook groups to establish social presence in online courses?. World Journal on Educational Technology: Current Issues, 9(4), 173-182.

Richardson, J. C., Maeda, Y., Lv, J., \& Caskurlu, S. (2017). Social presence in relation to students' satisfaction and learning in the online environment: A meta-analysis. Computers in Human Behavior, 71, 402-417.

Khodabandelou, R., Ab Jalil, H., Wan Ali, W. Z., \& bin Mohd Daud, S. (2014). Moderation Effect of Gender on Relationship between Community of Inquiry and Perceived Learning in Blended Learning Environments. Contemporary Educational Technology, 5(3), 257-271.

Kreijns, K., Van Acker, F., Vermeulen, M., \& Van Buuren, H. (2014). Community of inquiry: Social presence revisited. E-learning and Digital Media, 11(1), 5-18.

Lowenthal, P., \& Parscal, T. (2008). Teaching presence online facilitates meaningful learning. The Learning Curve, 3(4), 1-2.

Nguyen, T. (2015). The effectiveness of online learning: Beyond no significant difference and future horizons. MERLOT Journal of Online Learning and Teaching, 11(2), 309-319.

Persico, D., Pozzi, F., \& Sarti, L. (2010). Monitoring collaborative activities in computer supported collaborative learning. Distance Education, 31(1), 5-22.

Pillai, R., \& Sivathanu, B. (2019). An empirical study on the online learning experience of MOOCs: Indian students' perspective. International Journal of Educational Management. 
Rockinson-Szapkiw, A. J., Wendt, J., Whighting, M., \& Nisbet, D. (2016). The predictive relationship among the community of inquiry framework, perceived learning and online, and graduate students' course grades in online synchronous and asynchronous courses. International Review of Research in Open and Distributed Learning, 17(3), 18-35.

Rourke, L., Garrison, R., Anderson, T., \& Archer, W. (2000). Assessing teaching presence in a computer conference environment. University of Calgary.

Shea, P., \& Bidjerano, T. (2008). Measures of quality in online education: An investigation of the community of inquiry model and the net generation. Journal of Educational Computing Research, 39(4), 339-361.

Shea, P., \& Bidjerano, T. (2009). Community of inquiry as a theoretical framework to foster "epistemic engagement" and "cognitive presence" in online education. Computers \& Education, 52(3), 543-553.

Shea, P., \& Bidjerano, T. (2012). Learning presence as a moderator in the community of inquiry model. Computers \& Education, 59(2), 316-326.

Short, J., Williams, E., \& Christie, B. (1976). The social psychology of telecommunications. Toronto; London; New York: Wiley.

Traver, A. E., Volchok, E., Bidjerano, T., \& Shea, P. (2014). Correlating community college students' perceptions of community of inquiry presences with their completion of blended courses. The Internet and Higher Education, 20, 1-9. 